\title{
Structural Diagnosis and Performance Assessment of Existing Masonry Aqueducts with Unknown Geometry
}

\author{
Jiang $\mathrm{HU}^{\mathrm{a}, 1}$ and Fuheng $\mathrm{MA}^{\mathrm{a}}$ \\ ${ }^{a}$ State Key Laboratory of Hydrology-Water Resources and Hydraulic Engineering, \\ Nanjing Hydraulic Research Institute, Nanjing 210029, China
}

\begin{abstract}
Masonry arch aqueducts, as important hydraulic structures, constitute an meaningful part of old irrigation infrastructures in China. The constituent materials deteriorate over time, caused by weathering processes and the defect development, influences the mechanical performance of these structures. The paper presents a comprehensive approach to evaluate the structural safety of an old masonry aqueduct with uncertain mechanical parameters and unknown geometric dimensions. This approach employed the $3 \mathrm{D}$ terrestrial laser scanning (TLS) to measure the geometric dimensions, and the discrete element analysis (DEM) to analyze the current operational behaviour state of the masonry aqueduct. As a case study, the Zhaimen masonry arch aqueduct in the famous Red Flag Canal, operating for more than 50 years, was investigated in this study. Obvious defects, such as the continuous loss and falling of mortar and the arch ring detaching, appeared in this old aqueduct. The TLS measurement information was used to construct a DEM model. Then this numerical model was applied to analyze the current performance of the exiting masonry arch aqueduct. The results show that the upper structure and the supporting structure can still be stable assuming that the mortar with no bond strength. In other words, the deterioration of the mortar, due to natural weathering and Calcium ion dissolution caused by natural environment and leakage, would not have a fatal impact on the structural safety. The proposed structural diagnosis and performance assessment approach can provide a reference to safety evaluation for similar masonry arch aqueducts.
\end{abstract}

Keywords. Masonry arch, aqueduct; structural analysis, 3d terrestrial laser scanning, discrete element analysis

\section{Introduction}

Aqueduct plays an important role in irrigation infrastructures in China. The masonry arch aqueduct has the advantage of stable structure, large bearing capacity, and easy maintenance. Therefore, in the 1950s and 1960s, many stone masonry aqueducts were built to speed up the construction of large irrigation projects in China. Thousands of these masonry arch aqueducts, as important hydraulic structures of these old existing irrigation projects, are still in service. However, subjected to unfavorable factors, masonry arch aqueducts are deteriorating over long operation time. These unfavorable factors commonly include natural adverse conditions, extreme disaster events and poor

\footnotetext{
${ }^{1}$ Jiang Hu, State Key Laboratory of Hydrology-Water Resources and Hydraulic Engineering, Nanjing Hydraulic Research Institute, Nanjing, China; E-mail: huj@nhri.cn.
} 
maintenance. The coupled effect of the unfavorable factors gradually leads to material deterioration, damage development and serious deformations.

Analyzing the structural safety of the masonry arch aqueduct in service is a difficult task. The encountered difficulties are related to the uncertainty of geometries, materials and actions. There were often no design documents and no special structural analyses for these aqueducts constructed in 1950s and 1960s [1]. Due to the simplicity, speed and accuracy, terrestrial laser scanning (TLS) is replacing the traditional geometric techniques in engineering surveying [2]. According to the information from close range digital photogrammetry and ground probing radar, Lubowiecka et al. [3] defined a 3D model for a masonry structure with a complex geometry and unknown material properties, and then the numerical method was applied to analyze the structural behaviour.

Several methods, including FEM (finite element method), DDA (discontinuous deformation analysis) and DEM (discrete element method), are available for the structural safety diagnosis and the performance assessment of masonry arch structures [4-6]. FEM does not accurately represent the mechanical behaviour of masonry components, and often underestimates the load-carrying capacity. This results in uneconomical or unnecessary mitigation measures. DEM provides an advantageous alternative, and DDA is also specifically efficient in the modelling of the statics of masonry arches. Frequent changes in the connectivity of the masonry joints and the significant nonlinearity makes DEM a suitable approach for masonry arch structures with low or no bond strength.

Considering the unknown geometric dimensions and the uncertain mechanical parameters of historic masonry structures, the multidisciplinary approach integrating advanced measurement technologies and calculation methods should be applied to analyze their behaviour. In this paper, TLS was employed to measure the real 3D geometry of the whole existing masonry arch aqueduct. Then the DEM method was used to analyze the structural performance including the stability and the load-carrying capacity. As a case study, the Zhaimen masonry aqueduct was investigated in this paper.

\section{Comprehensive Structural Diagnosis and Performance Assessment Approach}

\subsection{Purpose and Challenge}

Figure 1 shows the common structural components of an existing masonry arch aqueduct. The main characteristics of a masonry arch aqueduct are the following: inhomogeneity, poor adhesion between mortars and stones, and high moisture content due to leakage. Due to the poor mechanical properties of the mortar (or lime) and their deterioration over time, the tensile strength of historic masonry is generally very low. Modeling and simulating the performance of a masonry arch aqueduct should satisfy the following requirements: adequately describing the geometry and morphology of the real structure, adopting constitutive equations allowing a reasonable description of the mechanical features of the materials, and containing existing defect information (cracks, disconnections, crushing, deformation and out-of-plumb etc.). 


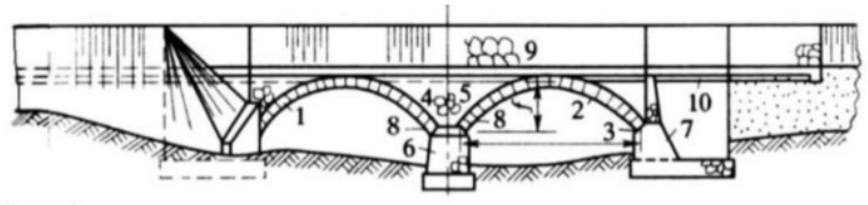

Legend

1. Arch ring; 2. Vault; 3. Arch foot; 4. External spandrel wall; 5. Fill; 6. Pier; 7. Skewback;

8. Drain pipe; 9. Aqueduct body; 10. Cushion

Figure 1. Common components of a existing masonry arch aqueduct.

\subsection{Structural Diagnosis and Performance Assessment Approach}

Figure 2 summarizes the proposed approach. The main steps are a complete survey, onsite visual investigations, field inspection and survey, and structural performance evaluation, finally, structural diagnosis and repair or reinforcement suggestions.

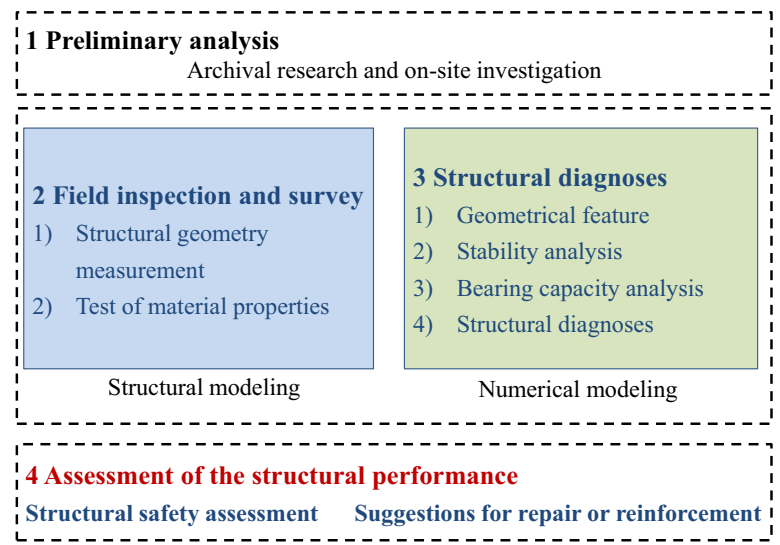

Figure 2. Multidisciplinary approach for performance assessment of existing masonry aqueducts.

\subsection{Field Inspection and Survey}

The TLS technique was used to measure an existing masonry aqueduct in this study. Several steps, including scan planning, data acquisition and registration (processing), triangulation and dimensioning (post-processing), and deformation analysis. Several issues, such as location and number of scans, resolution, occlusions and reference system etc., should be solved during the data acquisition and processing. Two coordinate systems, namely relative and absolute coordinate systems, intervene in TLS surveys.

The rebound method was employed to test the strength of the masonry mortar. When the test result of masonry mortar strength is less than $2.0 \mathrm{MPa}$ or more than 15.0 $\mathrm{MPa}$, it is not appropriate to give specific test values.

\subsection{Structural Diagnosis and Performance Assessment}

Explicit time marching is employed to directly solve the motion equations for the DEM code. The DEM method can be applied to model individual blocks connected by contact elements. It is capable of calculating large deformation, and simulating the 
complete detachment of discrete blocks. The DEM method is employed to capture the operation behaviour and failure mechanisms of existing masonry aqueducts. However, the computation results are sensitive to the mechanical properties of the contact elements, which are commonly uncertain for an old masonry aqueduct in service.

The discrete deformable inner-block elements, rectangles determined by actual dimensions, are assumed non-linear material describing by the common elastoplastic model. Inner-block elements are bonded together by zero thickness interfaces. Interfaces, where interactions among inner-blocks take place, would be the potential fracture slip surfaces. By sets of point contacts for the interfaces, one block is kinematically connected to another at locations where corners or edges meet, along the outside perimeter of the block. Interfaces, using the elastic-perfectly plastic coulomb slip-joint area contact option, were employed to simulate the mortar/lime joints in this study.

\section{Project Overview and Field Inspection}

\subsection{Project Overview}

The Red Flag Canal, located at the juncture of the three provinces of Henan, Shanxi and Hebei, is a famous irrigation canal in China. In April 1965, construction of this canal was completed. Though its design life was initially only 20 years, this irrigation canal is still in service today. After 1990, the deterioration of the canal has become obvious. The Zhaimen Aqueduct, consisting of two hole culverts, was investigated as a case in this study [7].

On-site investigations were performed. The aqueduct is generally leaky, especially in winter. The structural appearance of arch 1 is relatively good. However, the gap between the spandrel wall and the main arch ring is obvious. These two components are almost separated. Due to natural weathering, the lime mortar in the main arch ring is severely weathered. Caused by Calcium ion dissolution, the lime mortar is deteriorated. All these lead to the formation of holes and macro cracks. The cracks are widely distributed, and the interior is wet due to the upper aqueduct leakage. There are several obvious leakage points (greater than $0.5 \mathrm{ml} / \mathrm{min}$ ) at the bottom of the arch ring, lead to widely distributed white precipitates. Obvious deformation occurs in the structure of arch 1. Several masonry stones near the vault moved down seriously, and some of the masonry stones cracked. The groove piers on both sides are relatively intact, and no obvious defects are observed. But affected by serious leakage, the piers are also generally wet. Lime mortar in the middle pier is severely deteriorated, and is now powdery. According to the surveying records, stones in this arch ring are commonly disjointed. The maximum lime mortar loss depth and the maximum width of the middle pier of this arch ring are $17 \mathrm{~cm}$ and $6 \mathrm{~cm}$. Its maximum lime mortar loss depth is $14 \mathrm{~cm}$.

The weathering and spalling of the lime mortar in the main arch ring of arch 2 is severer than arch 1 . The lime mortar among masonry stones is almost lost. The maximum loss width of this arch ring reaches $15 \mathrm{~cm}$, and the maximum loss depth reaches $30 \mathrm{~cm}$. This arch is almost all wet. 


\subsection{Field Inspection and Survey}

Based on the field inspection data, the inferred strength of the inspected lime mortar of the masonry arch aqueduct is $2.1 \mathrm{MPa}$ with the corresponding standard deviation 1.3 $\mathrm{MPa}$. According to the geological survey result, figure 3 shows the geological profile for the aqueduct.

For the 3D surveying, a Leica ScanStation C10 3D laser scanner was used for the masonry arch aqueduct. Distances in a range of 1-300 $\mathrm{m}$, with a nominal accuracy of 2 $\mathrm{mm}-50 \mathrm{~m}$ in normal illumination and reflectivity conditions, can be measured by this laser sensor. The infrared laser has a wavelength of $532 \mathrm{~nm}$. The viewing field has $360^{\circ}$ horizontal and $270^{\circ}$ vertical amplitudes. The point acquisition rate is 50000 points per second. The accurate leveling of the final points cloud was obtained through a total station Leica TCA2003. The technical features of the instrument are as follows: $\pm(0.6 \mathrm{~mm}+1 \mathrm{ppm})$ accuracy; long-range measurements (up to $3000 \mathrm{~m}) ; 5 \mathrm{cc}$ angular accuracy. The registration process was performed using Leica Cyclone 8.1 software. Overall point cloud that has been registered has a maximum registration error of 0.005 m. Filtering process performed by fencing technique, which limit the area of the polygon lines, and determined the outside or the inside to be removed.

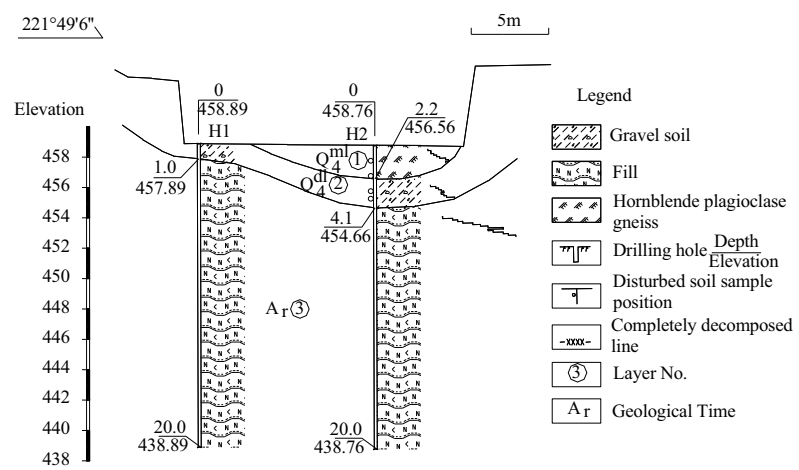

Figure 3. Engineering geological profile elevations, elevations are given in meters above sea level (m.a.s.l).

Four scan positions were performed for the TLS survey of the aqueduct. Two stations scanned the point cloud data around the aqueduct, and the other two stations scanned the internal main arch ring. Two scans were carried out from each scan position. Based on a minimum resolution (angular interval of $0.2^{\circ}$ ) scan of the entire field of vision, one scan was used for the obtaining of a general frame of the whole scanner field of view. On this basis, smaller areas can be selected for next scans. Selected from a two-dimensional (2D) view of the first scan, the other was of an area including the surface to be scanned. Then focusing on structural damages, detailed scans were carried out with a spatial resolution of $1 \mathrm{~mm}$. Because the stone surface was uneven, the laser would produce diffuse reflection, which would reduce the accuracy of the acquired data. The resolution of the instrument scan was set to $1 \mathrm{~mm}$ of spatial resolution. Since no target was placed during the scanning process, only point cloud stitching can be used for data stitching. The point with the same name could be set with higher accuracy, and the error of the final point cloud data stitching was also very small. The maximum error of point cloud data splicing was only $2 \mathrm{~mm}$. 
An independent coordinate system was adopted for the 3D TSL measurement. Both the outer contour and the deformation of the main arch ring of the masonry aqueduct were measured. Figure 4 shows the external dimensions of the masonry aqueduct. The typical cross sections and the corresponding elevations were measured. The global geometry of the masonry aqueduct was obtained. The aqueduct has a sagittal span of $1.25 \mathrm{~m}$, an arch span of $3.97 \mathrm{~m}$, a pier height of $0.97 \mathrm{~m}$, and an arch ring thickness of $0.33 \mathrm{~m}$. The aqueduct vector-span ratio is $1 / 3.176$ (greater than $1 / 5$ ), thus this aqueduct is a steep arch.

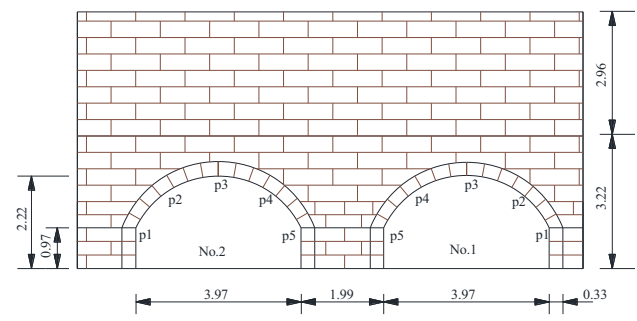

Figure 4. Cross section dimensions of the masonry arch aqueduct (unit: $\mathrm{m}$ ).

Based on the smoothness assumption of the structural surface, the deformation of the main arch rings was analyzed by the coordinate information. Five cross sections were taken from each arch. Figure 5 shows the deformation results of arch 1.

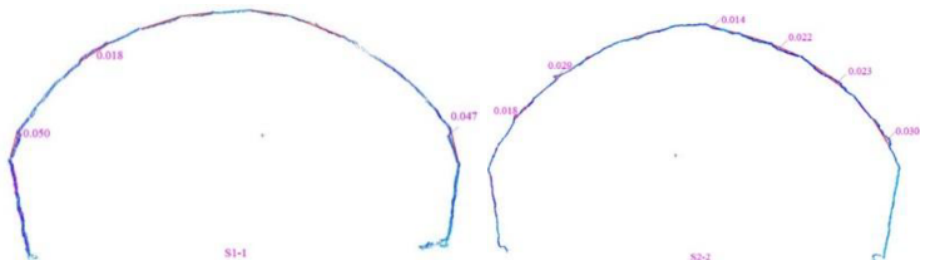

(a)

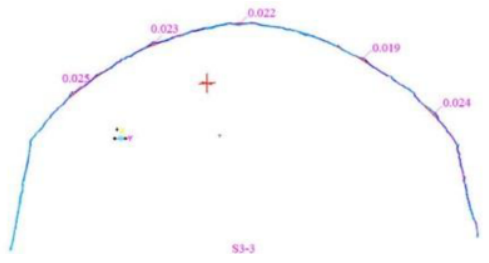

(c) (b)

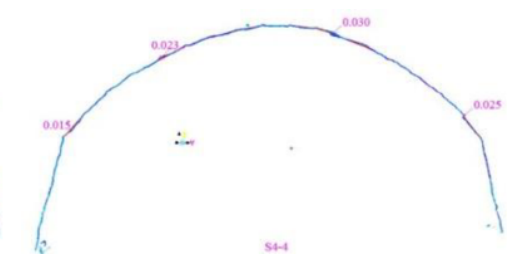

(d)

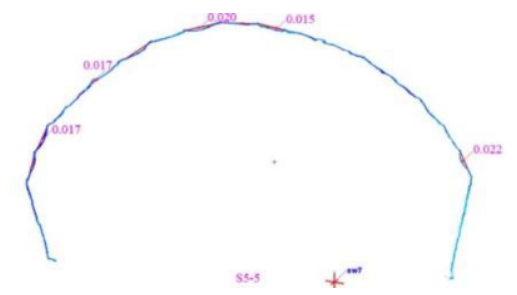

(e)

Figure 5. Deformation analysis results of arch 1: (a) 1-1; (b)2-2; (c)3-3; (d)4-4; and (e) 5-5. 
Table 1 and table 2 list surveying results of the cracks of the arch rings and the relative displacements of the main arch rings.

Table 1. Surveying results of the cracks of the arch rings.

\begin{tabular}{|c|c|c|c|c|c|c|c|c|c|}
\hline \multirow{2}{*}{ Arch } & \multirow{2}{*}{ Cross section } & \multicolumn{3}{|c|}{ Crack (mm) } & \multirow{2}{*}{ Arch } & \multirow{2}{*}{ Cross section } & \multicolumn{3}{|c|}{ Relative deformation (mm) } \\
\hline & & Width & Length & Depth & & & Width & Length & Depth \\
\hline \multirow{5}{*}{1} & 1 & 40 & 126 & 162 & \multirow{5}{*}{2} & 1 & 114 & 339 & 161 \\
\hline & 2 & 110 & 287 & 104 & & 2 & 81 & 241 & 224 \\
\hline & 3 & 153 & 220 & I & & 3 & 73 & 238 & 103 \\
\hline & 4 & 84 & 282 & l & & 4 & 67 & 342 & 191 \\
\hline & 5 & 98 & 264 & l & & 5 & 61 & 575 & 171 \\
\hline
\end{tabular}

Table 2. Measurement results of the relative displacements of the main arch rings.

\begin{tabular}{|c|c|c|c|c|c|}
\hline Arch & Cross section & Relative deformation (mm) & Arch & Cross section & Relative deformation (mm) \\
\hline \multirow{5}{*}{1} & 1 & 50.0 & \multirow{5}{*}{2} & 1 & 25.0 \\
\hline & 2 & 30.0 & & 2 & 31.0 \\
\hline & 3 & 27.0 & & 3 & 26.0 \\
\hline & 4 & 30.0 & & 4 & 77.0 \\
\hline & 5 & 22.0 & & 5 & 41.0 \\
\hline
\end{tabular}

\section{Structural Diagnosis and Performance Assessment}

\subsection{Numerical Model}

Based on the measured dimensions and the corresponding layers of masonry stones, a 2D DEM model was constructed (figure 6). According to the geological survey results (figure 3), the aqueduct foundation consists of layers of artificial soil, gravel soil, and thick gneiss from the top to the bottom. The thicknesses of the three layers are $2.2 \mathrm{~m}$, $1.5 \mathrm{~m}$ and $19.0 \mathrm{~m}$. The two vertical side boundaries of the model are horizontally fixed, and the bottom is vertically fixed. Other boundaries can move freely.

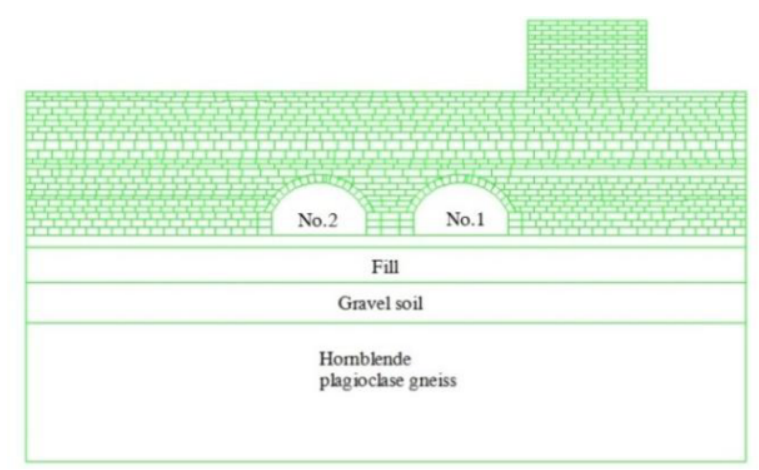

Figure 6. The DEM model of the investigated masonry aqueduct. 


\subsection{Stability Analysis}

The deterioration of lime mortar was considered in structural stability calculations. It was assumed that the mechanical parameters, namely the strength and the cohesion of the mortar, are lost in the current condition. Only the friction coefficient of the masonry stones sliding along joint was considered, and its value is 0.3 . Table 3 lists the mechanical and physical parameters of the masonry aqueduct and the foundation rock, and table 4 lists the mechanical parameters of the lime mortar.

Table 3. The physical and mechanical parameters of the masonry aqueduct and its foundation rock.

\begin{tabular}{llllll}
\hline Material & $\begin{array}{l}\text { Bulk modulus } \\
(\mathrm{GPa})\end{array}$ & $\begin{array}{l}\text { Shear modulus } \\
(\mathrm{GPa})\end{array}$ & $\begin{array}{l}\text { Cohesion } \\
(\mathrm{kPa})\end{array}$ & $\begin{array}{l}\text { Density } \\
\left(\mathrm{kg} \cdot \mathrm{m}^{-3}\right)\end{array}$ & $\begin{array}{l}\text { Internal friction angle } \\
\left({ }^{\circ}\right)\end{array}$ \\
\hline Masonry & 16.10 & 12.10 & $/$ & 2650.00 & $/$ \\
Gravel soil & 0.08 & 0.06 & 10.00 & 2280.00 & 20.00 \\
Gneiss & 12.80 & 9.58 & $/$ & 2650.00 & $/$ \\
\hline
\end{tabular}

Table 4. The mechanical parameters of the lime mortar among the masonry stones.

\begin{tabular}{lllll}
\hline $\begin{array}{l}\text { Normal stiffness } \\
(\mathrm{GPa} / \mathrm{m})\end{array}$ & $\begin{array}{l}\text { Shear stiffness } \\
(\mathrm{GPa} / \mathrm{m})\end{array}$ & $\begin{array}{l}\text { Internal friction angle } \\
\left({ }^{\circ}\right)\end{array}$ & $\begin{array}{l}\text { Cohesion } \\
(\mathrm{kPa})\end{array}$ & $\begin{array}{l}\text { Tensile strength } \\
(\mathrm{kPa})\end{array}$ \\
\hline 8.20 & 6.60 & 16.70 & 0.00 & 0.00 \\
\hline
\end{tabular}

For comparison analysis, five positions on arches 1 and 2 (figure 4) were respectively selected in the counterclockwise and clockwise directions, namely vault, and arch foot and 1/4 arch shoulder on both sides. Figure 7 shows the maximum and minimum stress distributions of the aqueduct.

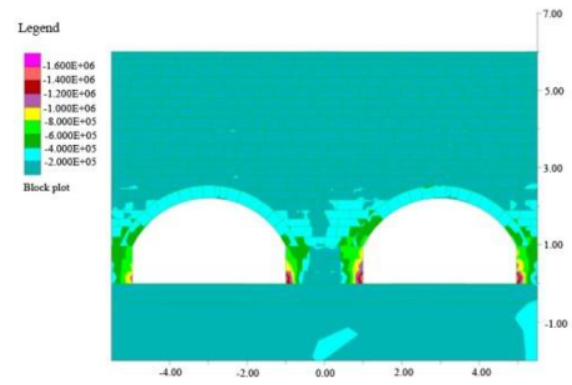

(a)

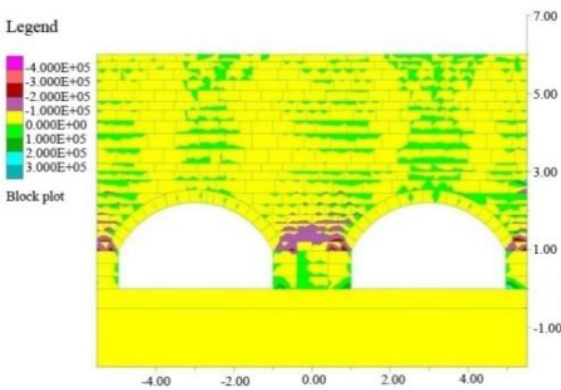

(b)

Figure 7. Principal stress distributions of the aqueduct: (a) minimum and (b) maximum principal stress.

Table 5 lists the calculated values. The calculated results show that the main compressive stress dominates the structural safety of the aqueduct. This is consistent with the force characteristics and the operation behaviour of the masonry arch. Despite the existence of tensile stress, the maximum value is only $0.1 \mathrm{MPa}$. The maximum principal compressive stress for the arch ring is $1.6 \mathrm{MPa}$, and this value occurs at positions 1 and 5. According to the inspection data, the current strength of the lime mortar is $2.1 \mathrm{MPa}$. The maximum principal stress of the arch ring is less than the current strength. Position 5 shows the phenomenon of stress concentrationt, which also 
conforms to the stress distribution of the masonry arch structure. Therefore, the lime mortar of the arch ring meets the strength requirement, and the masonry arch aqueduct is still stable in the current status. However, the design life of the project is 50 a, the minimum strength of the mortar should be $5 \mathrm{MPa}$ according to the specification. The estimated lime mortar strength from field inspection $(2.1 \mathrm{MPa})$ does not meet the requirement.

Table 5. Minimum principal stress for focused positions of the masonry arch.

\begin{tabular}{llllll}
\hline Position & 1 & 2 & 3 & 4 & 5 \\
\hline Arch 1 & 1.60 & 0.26 & 0.20 & 0.28 & 1.60 \\
\hline Arch 2 & 1.60 & 0.24 & 0.22 & 0.28 & 1.60 \\
\hline
\end{tabular}

\subsection{Bearing Capacity Analysis of Foundation}

Figure 8 shows the settlement result of the aqueduct. The maximum settlement of the structure is $8 \mathrm{~mm}$, and appears at the vault of the arch ring of arch 1 . The absolute maximum value of the minimum principal stress of the foundation appears at the pier foot of the arch 2, in the range of 200 to $230 \mathrm{kPa}$. The allowable bearing capacity of the foundation is $300 \mathrm{kPa}$, thus the bearing capacity of the aqueduct foundation also meets the operational requirements.

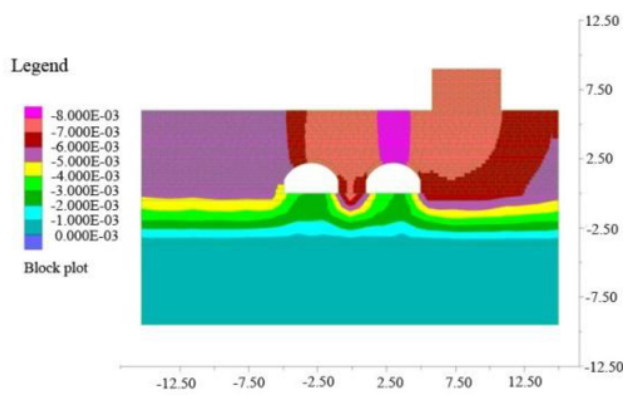

Figure 8. Vertical displacement distribution of the masonry aqueduct in the case of intact structure.

For comparative analysis, the hingeless arch calculation method was also used to analyze the foundation stability. In addition to self-weight, considering the full tank water pressure and pedestrian pressure, the maximum value is $280 \mathrm{kPa}$. The allowable bearing capacity characteristic value is $300 \mathrm{kPa}$, and the foundation bearing capacity meets the requirements. The overall anti-sliding stability coefficient is 2.69 , which is greater than 1.2 required by the code, and the foundation meets the requirements.

\subsection{Result Discussions and Treatment Suggestions}

According to the field inspection and the numerical results, it can be known that the aqueduct has hidden dangers such as the upper structure detaching from the arch ring and the continuous lime mortar shedding. In the condition of lime mortar deterioration, the supporting structure and the aqueduct arch ring, and the upper structure are still stable according to conservative calculations. 
In order to improve the compactness among the masonry stones, chemical grouting using material with good durability and large elastic modulus should be timely carried out to fill the masonry joints to prevent excessive deformation. Anti-seepage measures at the bottom of the aqueduct should also be taken as soon as possible to stop the serious leakage, and to slow down the lime mortar deterioration caused by long-term erosion action.

\section{Conclusions}

Some problems encountered when assessing existing masonry aqueducts were solved in this paper. The TLS was employed to build a relatively accurate DEM model. The DEM model was applied to assess performance and diagnose structural safety.

TLS is an appropriate and accurate technique for existing structural dimension measurement and defect detection. The information resulting from TLS results can be used to construct a reliable structural model, and useful for simulation of the operation behaviour of the stone masonry aqueduct.

The stability of the old stone masonry aqueduct is not significantly affected by deterioration of the mortar. However, in order to prevent uneven deformation of the structure, grouting of the laying joints among the masonry stones should be timely carried out for the masonry arch aqueduct. In order to avoid the serious erosion of the mortar, anti-seepage measures at the bottom of the aqueduct should also be taken to prevent the leakage of the aqueduct in time.

\section{Acknowledgements}

This research was supported by the National Natural Science Foundation of China (grant no. 51879169; 52179138), and the Fundamental Research Funds for the Central Public Welfare Research Institute (No. Y20002; Y20003). The authors wish to acknowledge the support of the Red Flag Canal Management Office. The authors thank Haijun Wang and Peiying Gu for their technical supports.

\section{References}

[1] Wang J, Zhu Y, Sun T, Huang J, Zhang L, Guan B, Huang QQ. Forty years of irrigation development and reform in china. Aust J Agr Resour Ec. 2020 Jan; 64(1):126-149.

[2] Dabous SA, Feroz S. Condition monitoring of bridges with non-contact testing technologies. Automat Constr. 2020 Aug; 116: 103224.

[3] Lubowiecka I, Arias P, Riveiro B, Solla M. Multidisciplinary approach to the assessment of historic structures based on the case of a masonry bridge in Galicia (Spain). Comput Struct. 2011 Sept; 89(1718): 1615-1627.

[4] Portioli F, Cascini L. Large displacement analysis of dry-jointed masonry structures subjected to settlements using rigid block modeling. Eng Struct. 2017 Oct; 148: 485-496.

[5] Pulatsu B, Bretas EM, Lourenco PB. Discrete element modeling of masonry structures: validation and application. Earthq Struct. 2016 Oct; 11(4): 563-582.

[6] Roca P, Cervera M, Gariup G, Pela L. Structural analysis of masonry historical constructions. Classical and advanced approaches. Arch Comput Method E. 2010 Sep; 17(3): 299-325.

[7] Hu J, Ma F. Safety assessment of red flag canal, Nanjing: Nanjing Hydraulic Research Institute; 2019 Oct; p. 131-140. 